\title{
Differences between human subjects in the composition of the faecal bacterial community and faecal metabolism of linoleic acid
}

\author{
Correspondence \\ R. John Wallace \\ John.Wallace@rowett.ac.uk
}

Received 18 August 2008

Revised 31 October 2008

Accepted 2 November 2008

\author{
Estelle Devillard, ${ }^{1} \dagger$ Freda M. Mclntosh, ${ }^{1}$ Delphine Paillard, ${ }^{1}$ \\ Nadine A. Thomas, ${ }^{1}$ Kevin J. Shingfield ${ }^{2}$ and R. John Wallace ${ }^{1}$ \\ ${ }^{1}$ Rowett Research Institute, Greenburn Road, Bucksburn, Aberdeen AB21 9SB, UK \\ ${ }^{2}$ Animal Production Research, MTT Agrifood Research Finland, 31600, Jokioinen, Finland
}

\section{INTRODUCTION}

Conjugated linoleic acid (CLA) is a collective term used to describe positional and geometric isomers of linoleic acid (LA; cis-9,cis-12-18:2) containing a conjugated double bond. Evidence derived from studies in animal models and clinical trials indicates that CLA could have a number of beneficial effects on human health, including decreasing carcinogenesis and atherosclerosis, controlling body fat gain and enhancing the immune response as well as decreasing inflammation and other adverse effects typically associated with immune enhancement (McLeod et al., 2004; O'Shea et al., 2004; Wang \& Jones, 2004; Lee et al., 2005; Tricon et al., 2005).

†Present address: ADISSEO France SAS, Route de Chamblet, 03600 Commentry, France.

Abbreviations: CLA, conjugated linoleic acid; DMOX, 4,4-dimethyloxazoline fatty acid derivatives; FAME, fatty acid methyl ester; LA, linoleic acid (cis-9,cis-12-18 : 2); MUFA, monounsaturated fatty acid; PUFA, polyunsaturated fatty acid; RA, rumenic acid (cis-9,trans-11-18:2); SA, stearic acid (18:0); SCFA, short-chain fatty acid; VA, vaccenic acid (trans-11-18:1).
The main source of CLA in man is ruminant-derived foods (Lawson et al., 2001). CLA may also be formed during metabolism of LA by intestinal bacteria, as demonstrated in rats (Eyssen \& Parmentier, 1974; Chin et al., 1994; Ewaschuk et al., 2006) and man (Howard \& Henderson, 1999; Devillard et al., 2006; Kamlage et al., 1999, 2000). CLA shows anti-inflammatory properties with colonocytes (Hontecillas et al., 2002; Bassaganya-Riera et al., 2004; Bassaganya-Riera \& Hontecillas, 2006), and therefore could be therapeutic for inflammatory bowel diseases, including ulcerative colitis and Crohn's disease. It has also been suggested that CLA inhibits the development of colorectal cancer (Cho et al., 2005; Lampen et al., 2005; Lee et al., 2005; Beppu et al., 2006). Positional and geometric isomers of CLA may have different physiological effects in humans (Tricon et al., 2005). It is therefore important to understand the formation of specific isomers of CLA during LA metabolism in relation to gut health.

Pure-culture studies indicated that the most active LAmetabolizing bacteria in the human intestine were Roseburia spp. and Butyrivibrio fibrisolvens (Devillard et al., 2007). Roseburia inulinivorans and Roseburia hominis 
formed vaccenic acid (VA; trans-11-18:1), as did $B$. fibrisolvens. Other Roseburia spp. formed a hydroxy 18:1 fatty acid, which was converted subsequently to VA. In contrast, Propionibacterium and Bifidobacterium spp. formed a mixture of CLA isomers. As the proportion of predominant bacterial species varies between individuals (Zoetendal et al., 1998; Eckburg et al., 2005; Duncan et al., 2007; Flint et al., 2007), we considered it plausible that LA metabolism might vary in a similar way, with possible implications for gut health. Preliminary experiments were carried out with faecal samples from a panel of human volunteers, from which two were selected as having different biohydrogenation characteristics. Here we report detailed analysis of faecal CLA formation and community structure in those individuals, which offers an insight into how LA metabolism and potential consequences on human health may vary according to the intestinal bacterial population.

\section{METHODS}

Donors and sample collections. Faecal samples were collected from two healthy 33-year-old females. The volunteers had no history of gastrointestinal disorders and no antibiotic treatment during the 2 months preceding the study. The diets of the two subjects were not controlled, though both consumed diets that would be considered typical of a Western diet. Freshly voided faeces were collected in sterile containers and were used in incubations with fatty acid substrates within $1 \mathrm{~h}$ of collection. Subsamples were stored at $-20{ }^{\circ} \mathrm{C}$ for later DNA extraction and short-chain fatty acid (SCFA) determinations.

Incubation of faecal samples with LA. Experiments were conducted in $12.5 \times 1.5 \mathrm{~cm}$ culture tubes equipped with screw caps and butyl rubber septa (Bellco Biotechnology) to maintain anaerobic $\left(\mathrm{CO}_{2}\right)$ conditions during incubations. Fresh samples of faeces were homogenized, and subsamples (between 2 and $4 \mathrm{~g}$ ) were transferred into sterile $50 \mathrm{ml}$ tubes. Then $0.1 \mathrm{M}$ potassium phosphate anaerobic buffer, $\mathrm{pH} 7.0$, was added to obtain a final suspension of $0.1 \mathrm{~g}$ faecal sample per $\mathrm{ml}$. The diluted sample was homogenized three times for $1 \mathrm{~min}$ on ice (Ultra Turrax, IKA-Werke) and filtered through three layers of muslin cloth to remove large particles. At time $0,5 \mathrm{ml}$ of the suspension was transferred into a tube maintained at $37{ }^{\circ} \mathrm{C}$ under $\mathrm{CO}_{2}$ and containing $100 \mu \mathrm{l}$ of an aqueous solution of $25 \mathrm{mg} \mathrm{LA} \mathrm{ml}^{-1}$ (Sigma) prepared by sonication. Immediately, a $1 \mathrm{ml}$ aliquot was removed from the incubation mixture. To prevent further metabolic activity, the samples were heated at $100{ }^{\circ} \mathrm{C}$ for $10 \mathrm{~min}$. The remainder was incubated under $\mathrm{CO}_{2}$ at $37{ }^{\circ} \mathrm{C}$, with samples being collected at 1 , 4 , and $8 \mathrm{~h}$. Each incubation was performed in triplicate.

Fatty acid extraction and analysis. Following the addition of internal standard (C19:0), samples were saponified in $2 \mathrm{M} \mathrm{NaOH}$ for $30 \mathrm{~min}$ at $85{ }^{\circ} \mathrm{C}$ (Devillard et al., 2006). Use of pure unsaturated fatty acids standards treated or not with $2 \mathrm{M} \mathrm{NaOH}$ for $30 \mathrm{~min}$ at $85^{\circ} \mathrm{C}$ (results not shown) was used to verify that the saponification procedure liberated non-esterified fatty acids from complex lipids, without causing isomerization of long-chain unsaturated fatty acids. Fatty acids were extracted using a mixture of methanol and chloroform (Folch et al., 1957), converted to fatty acid methyl esters (FAMEs) using $1 \%(\mathrm{v} / \mathrm{v})$ methanolic sulphuric acid as a catalyst, and analysed by GC (Devillard et al., 2006; Waşowska et al., 2006). Experimental data were analysed by two-way ANOVA (Genstat 8th edition, release 8.1 ; VSN International) using a model that included the fixed effects of sampling time, random effects of volunteer and their interaction. Least-square means are reported and treatment effects were considered significant at $P<0.05$.

Identification of CLA isomers. Formal structural identification of CLA formed during in vitro incubations was based on GC-MS analysis of 4,4-dimethyloxazoline (DMOX) fatty acid derivatives. DMOX derivatives were prepared from selected samples of FAMEs using 2-amino-2-methyl-1-propanol $(500 \mu \mathrm{l})$ and heating overnight under a nitrogen atmosphere according to Fay \& Richli (1991), with the exception that a temperature of $150{ }^{\circ} \mathrm{C}$ was used (Shingfield et al., 2006). GC-MS analysis of DMOX derivatives was performed using a gas chromatograph (6890; Hewlett Packard) equipped with a $100 \mathrm{~m}$ CP-SIL 88 column and selective quadrupole mass detector (model $5973 \mathrm{~N}$, Agilent Technologies), under an ionization voltage of $70 \mathrm{eV}$ using helium as the carrier gas. Both the ion source and interface temperatures were maintained at $230{ }^{\circ} \mathrm{C}$. DMOX derivatives in a $4 \mu \mathrm{l}$ sample were injected at a split ratio of $1: 50$ and separated using a temperature gradient with a total run time of $98.5 \mathrm{~min}$. Following sample injection, column temperature was maintained at $70{ }^{\circ} \mathrm{C}$ for $4 \mathrm{~min}$, increased at a rate of $8 \mathrm{C}^{\circ} \mathrm{min}^{-1}$ to $110{ }^{\circ} \mathrm{C}$, raised to $170{ }^{\circ} \mathrm{C}$ at a rate of $5 \mathrm{C}^{\circ} \mathrm{min}^{-1}$, held at $170{ }^{\circ} \mathrm{C}$ for $10 \mathrm{~min}$, and then increased at a rate of $4 \mathrm{C}^{\circ} \mathrm{min}^{-1}$ to a final temperature of $240{ }^{\circ} \mathrm{C}$ that was maintained for $50 \mathrm{~min}$. Electron impact ionization spectra obtained were used to locate double bonds based on atomic mass unit distances, with an interval of 12 atomic mass units between the most intense peaks of clusters of ions containing $n$ and $n-1$ carbon atoms being interpreted as cleavage of the double bond between carbon $n$ and $n+1$ in the fatty acid moiety. Identification was further validated by comparison with an online reference library of DMOX electron impact ionization spectra (http://www.lipidlibrary.co.uk). Implied double-bond geometry of CLA isomers based on GC-MS analysis was verified by silver-ion HPLC analysis of the parent FAME used to prepare DMOX derivatives. Analysis was performed using an HPLC system (model 1090; Hewlett Packard) equipped with photodiode array detector and four silver-impregnated silica columns (ChromSpher 5 Lipids, $250 \times 4.6 \mathrm{~mm}, 5 \mu \mathrm{m}$ particle size; Varian) coupled in series. Methyl esters of CLA were separated under isocratic conditions at $22{ }^{\circ} \mathrm{C}$ using $0.1 \%(\mathrm{v} / \mathrm{v})$ acetonitrile in heptane at a flow rate of $1 \mathrm{ml} \mathrm{min}^{-1}$ (total run time $100 \mathrm{~min}$ ) and monitoring column effluent at 233 and 210 (reference wavelength) nm (Shingfield et al., 2003).

Determination of faecal SCFA concentrations. Diluted faecal samples $\left(0.1 \mathrm{~g} \mathrm{ml}^{-1}\right.$ in $0.1 \mathrm{M}$ phosphate buffer $\left.\mathrm{pH} 7.0\right)$ were analysed in triplicate for SCFA concentrations. After homogenization, samples were centrifuged $(10000 \mathrm{~g}$ for $10 \mathrm{~min})$ and the supernatants containing SCFAs were recovered. After conversion to $t$-butyldimethylsilyl derivatives, the SCFAs were analysed by GC according to Richardson et al. (1989).

Extraction of total DNA. Total DNA was extracted from $200 \mu \mathrm{l}$ of faecal suspensions $\left(0.1 \mathrm{~g} \mathrm{ml}^{-1}\right.$ in $0.1 \mathrm{M}$ phosphate buffer $\left.\mathrm{pH} 7.0\right)$ using the established protocol for isolating DNA from faeces for pathogen detection (QIAmp DNA stool kit; Qiagen). Concentrations of DNA were estimated at $260 \mathrm{~nm}$, and DNA integrity was verified by agarose gel electrophoresis $(0.8 \%$ agarose in $1 \times$ Tris/borate/EDTA buffer).

Amplification, cloning and sequencing of 16S rRNA genes. 16S rRNA genes were amplified as described by Suau et al. (1999), using the same primers (S-D-Bact-0008-a-S-20 and S-*-Univ-1492-b-A-21) and the same PCR conditions, which included a low number of amplification cycles ( 10 cycles) to avoid bias due to the amplification. After the PCR, six tubes of $50 \mu \mathrm{l}$ each were pooled, purified and concentrated with the QIAquick spin PCR purification kit (Qiagen). The concentration and the size of the purified PCR products were 
estimated by agarose electrophoresis. Purified PCR products were cloned into the pCR4-TOPO vector using the TOPO TA cloning kit (Invitrogen). Chemically competent Escherichia coli TOP10 cells were transformed with the ligation products by heat shock $\left(30 \mathrm{~s}\right.$ at $\left.42{ }^{\circ} \mathrm{C}\right)$. Recombinant cells were selected on Luria-Bertani medium with kanamycin $\left(50 \mu \mathrm{g} \mathrm{ml}^{-1}\right)$ and X-Gal $\left(40 \mu \mathrm{g} \mathrm{ml}^{-1}\right)$. One hundred white colonies were transferred to $200 \mu \mathrm{l}$ Luria-Bertani broth containing $50 \mu \mathrm{g}$ kanamycin $\mathrm{ml}^{-1}$.

Inserts were amplified directly from $1.5 \mu \mathrm{l}$ of cultures using the primers on the pCR4-TOPO vector (T7 promoter primer and M13 reverse primer). PCR products were cleaned up using a Montage PCR96 plate (Millipore) in accordance with the recommendations of the manufacturer. Finally, purified PCR products were sequenced using the primer S-D-Bact-0008-a-S-20, on a Beckman Coulter CEQ 8000 DNA analyser.

rRNA sequence analysis. The $16 \mathrm{~S}$ rRNA sequences from the clone libraries were compared to the public database Ribosomal Database Project (RDP, http://rdp.cme.msu.edu/). The classifier from RDP was used to assign 16S rRNA sequences to the taxonomical hierarchy proposed in Bergey's Manual of Systematic Bacteriology, release 6.0 (Cole et al., 2005). Hierarchical taxa are based on a naïve Bayesian rRNA classifier. Analysis of the 16S rRNA sequences was also performed using the GenBank DNA database and the BLAST algorithm.
Detection of stearate-producing bacteria by real-time PCR. The oligonucleotides used to detect stearate-producing bacteria were designed to detect the DNA from ruminal stearate-producing bacterial strains from a group-specific region on the 16S rRNA gene (Paillard et al., 2007). Dilutions of purified genomic DNA from the control strain Clostridium proteoclasticum P-18 were used to construct specific calibration curves. Amplification was carried out in a final volume of $25 \mu$ l containing $12.5 \mu \mathrm{l}$ iQ Supermix (Bio-Rad), 400 and $800 \mathrm{nM}$ forward and reverse primer respectively, $250 \mathrm{nM}$ probe, and $2.5 \mu \mathrm{l}$ purified genomic DNA. Amplification $\left(10 \mathrm{~min}\right.$ at $95^{\circ} \mathrm{C}$, then 40 cycles of three steps consisting of $30 \mathrm{~s}$ at $95{ }^{\circ} \mathrm{C}, 1 \mathrm{~min}$ at $55^{\circ} \mathrm{C}$ and $30 \mathrm{~s}$ at $72{ }^{\circ} \mathrm{C}$ ) was performed with the iCycler iQ thermal cycler (Bio$\mathrm{Rad})$. Fluorescence data were obtained at the end of the hybridization step, at excitation and emission wavelengths of 490 and $530 \mathrm{~nm}$, respectively. All samples were run in triplicate. Results were analysed using the iCycler iQ detection system software (Bio-Rad).

\section{RESULTS}

\section{Fatty acid composition of faecal samples}

The fatty acid composition of the faecal samples from the two human volunteers was determined in the zero-time samples from incubations with LA (Table 1). The total

Table 1. Metabolism of LA by diluted faecal suspensions collected from two human volunteers

The initial LA concentration was $500 \mu \mathrm{g} \mathrm{ml}^{-1}$ of $10 \%$ (wet w/v) faecal suspension. Results are expressed as $\mu \mathrm{g}$ fatty acid per g of faecal sample and represent the mean of three determinations; NA, not applicable.

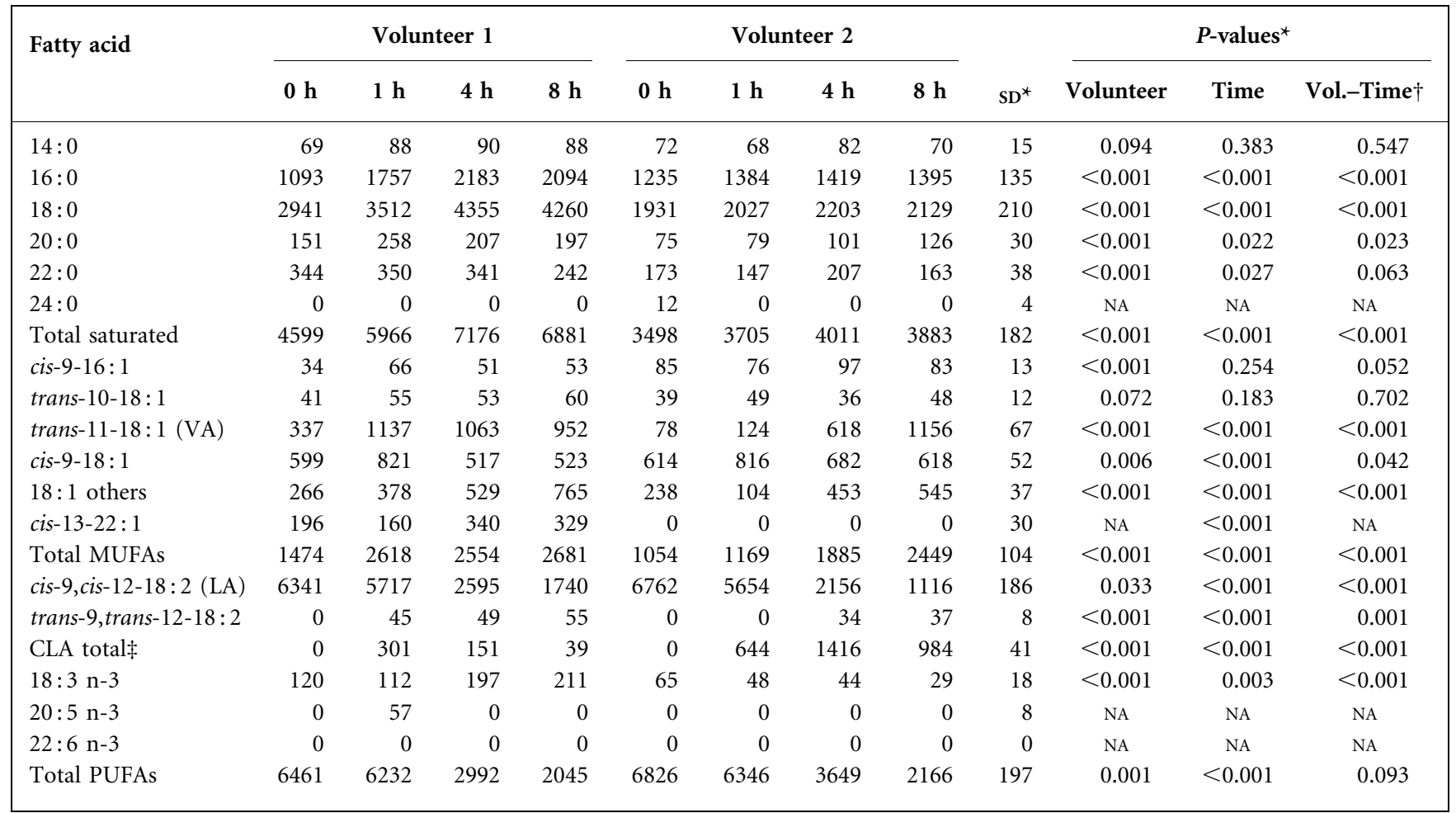

*Analysed by two-way ANOVA with a model that included the effects of volunteer, time and their interaction. Residual SD based on ANOVA output.

$\dagger$ Volunteer-time interaction.

$\ddagger$ See Table 2 for composition. 
saturated fatty acid concentrations were higher in V1 than V2 (4.6 vs $3.5 \mathrm{mg} \mathrm{g}^{-1}$ ), containing predominantly $16: 0$, $18: 0$ and $22: 0$. Oleic acid (cis-9-18:1) was the most abundant monounsaturated fatty acid (MUFA), at comparable concentrations in both samples. In contrast, VA concentrations in V1 were 4.3-fold higher than in V2. PUFA concentrations were similar between samples and consisted mainly of the LA that had been added to the suspensions (Table 1). CLA was not detectable.

\section{LA metabolism by human faecal flora}

LA was metabolized at similar rates in the incubations of faecal samples from the two volunteers (Table 1). CLA accumulated to a much greater extent in V2 compared to $\mathrm{V} 1$, whereas VA accumulation was more rapid in V1 than V2. Stearic acid (SA; 18:0) formation was also much higher in V1 than V2, where SA formation was minimal. Palmitic acid (16:0) concentration also doubled in V1, while little if any was formed with V2.

There were marked differences between the two volunteers in the profile of CLA isomers produced (Table 2). A total of 12 isomers were detected in V2, compared with six in V1. In V1, rumenic acid (RA; cis-9,trans-11-18:2) was the predominant isomer throughout, with trans-10,cis-12-18:2 being less than one-tenth of the RA concentration. trans9,trans-11-18:2 was present at similar concentrations to trans-10,cis-12-18:2 in V1. In contrast, trans-10,cis-12-
18:2 was a much higher proportion of total CLA in V2, and even exceeded RA in concentration at $8 \mathrm{~h}$.

\section{Concentrations of SCFAs in faecal samples}

Total concentrations of SCFAs in faecal samples from V1 and V2 were $86.7 \mathrm{mM}$ and $68.7 \mathrm{mM}$, respectively (Table 3 ). The major SCFAs (acetate, butyrate and propionate) accounted for $91.6 \%$ and $89.4 \%$ of the total SCFA in V1 and V2, respectively. Other SCFAs, including isobutyrate, isovalerate, valerate, caproate and succinate, were also detected, but all samples were devoid of lactate. Proportions of propionate and butyrate in total SCFAs were higher in V1 compared with V2, with acetate/ propionate/butyrate molar ratios of 58.9/17.2/15.5 and $63.5 / 13.9 / 12$, respectively.

\section{Assessment of bacterial diversity in faecal samples}

Faecal samples from the two volunteers were also analysed for bacterial composition. Two hundred colonies were used for 16S rRNA gene sequencing, from which 91 sequences for each sample were analysed further. The average length of the sequences obtained was $800 \mathrm{bp} ; 650-700 \mathrm{bp}$ were used for sequence analysis. All the sequences belonged to the main phyla of bacteria found in the human gut, namely Firmicutes, Bacteroidetes and Actinobacteria (Table 4). The

Table 2. Distribution of CLA isomers formed during the incubation of LA with diluted faecal samples collected from two human volunteers

Results are expressed as percentages of total CLA present in the samples; -, not detected

\begin{tabular}{|c|c|c|c|c|c|c|c|c|}
\hline & \multicolumn{4}{|c|}{ Volunteer 1} & \multicolumn{4}{|c|}{ Volunteer 2} \\
\hline & $\mathbf{0 h}$ & $1 \mathrm{~h}$ & $4 \mathrm{~h}$ & $8 \mathrm{~h}$ & $\mathbf{O} \mathbf{h}$ & $1 \mathrm{~h}$ & $4 \mathrm{~h}$ & $8 \mathrm{~h}$ \\
\hline trans-6,trans-8-18:2 & - & - & - & - & - & - & - & - \\
\hline trans-7,cis-9-18:2 & - & - & - & - & - & - & - & - \\
\hline trans-7,trans-9-18:2 & - & - & - & - & - & - & - & - \\
\hline cis-8,cis-10-18:2 & - & - & - & - & - & - & - & 1 \\
\hline trans-8,cis-10-18:2 & - & - & - & - & - & - & - & - \\
\hline trans-8,trans-10-18:2 & - & - & - & - & - & - & - & - \\
\hline cis-9,cis-11-18:2 & - & - & 0.9 & 1.4 & - & 2.3 & 9.4 & 1.1 \\
\hline cis-9,trans-11-18:2 & - & 100 & 80.3 & 75 & - & 57.4 & 44.7 & 35.7 \\
\hline trans-9,cis-11-18:2 & - & - & - & - & - & - & - & - \\
\hline trans -9, trans $-11-18: 2$ & - & - & 6.6 & 12.4 & - & 7.8 & 13.6 & 8.3 \\
\hline cis-10,cis-12-18:2 & - & - & - & 0.9 & - & - & - & 1.5 \\
\hline trans-10,cis-12-18:2 & - & - & 7.1 & 6.9 & - & 28.4 & 25.7 & 44.2 \\
\hline trans -10, trans $-12-18: 2$ & - & - & 5.2 & 3.4 & - & 4.2 & 1.3 & 6.9 \\
\hline cis-11,cis-13-18:2 & - & - & - & - & - & - & - & 0.8 \\
\hline cis-11,trans-13-18:2 & - & - & - & - & - & - & - & - \\
\hline trans-11,cis-13-18:2 & - & - & - & - & - & - & 3.2 & 0.6 \\
\hline trans -11, trans $-13-18: 2$ & - & - & - & - & - & - & 0.6 & - \\
\hline cis-12,trans-14-18:2 & - & - & - & - & - & - & 1 & - \\
\hline trans-12,cis-14-18:2 & - & - & - & - & - & - & 0.7 & - \\
\hline
\end{tabular}


Table 3. Molar proportions of SCFAs in faecal samples V1 and V2

Results reported represent the mean of three determinations and are expressed as a percentage of total SCFAs. Total concentrations of SCFAs in faecal samples from $\mathrm{V} 1$ and $\mathrm{V} 2$ were $86.7 \mathrm{mM}$ and $68.7 \mathrm{mM}$, respectively.

\begin{tabular}{|lccccc|}
\hline \multirow{2}{*}{ SCFA } & \multicolumn{3}{c|}{ Percentage of total SCFAs } \\
\cline { 2 - 3 } & \multicolumn{2}{c}{ Volunteer 1} & & \multicolumn{2}{c|}{ Volunteer 2} \\
\cline { 2 - 3 } \cline { 5 - 6 } & Mean & SD & & Mean & SD \\
\cline { 2 - 3 } Succinate & 0.0 & & & 0.5 & 0.1 \\
Caproate & 2.2 & 0.4 & & 2.5 & 0.3 \\
Valerate & 2.6 & 0.2 & & 1.9 & 0.2 \\
Iso-valerate & 1.5 & 0.2 & & 1.8 & 0.3 \\
Iso-butyrate & 2.2 & 0.3 & & 2.9 & 0.4 \\
Butyrate & 15.5 & 1.7 & & 12.0 & 1.5 \\
Propionate & 17.2 & 1.9 & & 13.9 & 1.3 \\
Acetate & 58.9 & 8.2 & 63.5 & 10.1 \\
\hline
\end{tabular}

proportions of sequences assigned to these different phyla compared to the total sequences analysed were different for the two volunteers. Bacteroidetes predominated in V1 (53.8\% of the clones), whereas the major bacterial population in V2 belonged to the Firmicutes phylum (65.9\% of the clones). V2 also contained small numbers of bacteria from the phylum Actinobacteria ( $4.4 \%$ of the total sequences), which were not present in V1. In addition, there were large variations within the two main phyla between the samples analysed. Some bacterial families were absent from the clone library of V1, such as Eubacteriaceae and Rikenellacae, or from the clone library of V2, such as Prevotellaceae.

A real-time PCR approach was used to estimate the population of $C$. proteoclasticum in faecal samples. The design of the method to target this specific bacterial population was based on sequences from ruminal bacteria. No bacteria corresponding to this specific group of SA producers were detected in the DNA extracted from either faecal sample.

\section{DISCUSSION}

This study was undertaken against a background of exploiting potential health benefits from enhancing CLA formation from LA in the human colon, either as therapy for inflammatory bowel disease or as a prophylactic with respect to colonic cancer. The aim was to assess how different compositions of the indigenous bacterial community of the human intestine could affect the formation of different isomers of CLA. There is an increasing body of evidence indicating that positional and geometric isomers of CLA exert different physiological effects in humans (Tricon et al., 2005). The present study reports, we believe for the first time, that at least 12 different isomers of CLA can be produced from LA by the colonic microflora, and that CLA production varies between individuals. In particular, trans-10,cis-12-18:2, which has possible detrimental effects on health (Clement et al., 2002; Wahle et al., 2004), may become the predominant isomer formed depending on the bacterial population colonizing the intestine. The physiological effects of most other CLA isomers are unknown. Production of VA may elicit similar benefits to human gut health to RA, since VA can be converted to RA in mammalian tissues, including intestinal cells (Miller et al., 2003). Thus, the accumulation of VA in V1 could be considered positive with regard to human health, whereas the mixture of CLA isomers accumulating in V2 would be much less clearly positive.

The pattern of LA metabolism observed here for V1 was consistent with previous studies reporting that the main route of LA in intestinal bacteria involves the isomerization of LA to RA, followed by sequential reduction of RA to VA

Table 4. Identity of clones retrieved from $16 \mathrm{~S}$ rDNA libraries made from faecal samples V1 and V2

\begin{tabular}{|lccl|}
\hline & \multicolumn{2}{c|}{ Percentage of clones } & \multicolumn{1}{c|}{ Related genera } \\
\cline { 2 - 3 } & V1 & V2 & \\
\hline Phylum Firmicutes & $\mathbf{4 6 . 2}$ & $\mathbf{6 5 . 9}$ & \\
Family Clostridiaceae & 8.8 & 23.1 & Faecalibacterium, Clostridium \\
Family Lachnospiraceae & 24.2 & 19.8 & Lachnospira, Roseburia, Butyrivibrio \\
Family Acidaminococcaceae & 8.8 & 4.4 & Dialister \\
Family Eubacteriaceae & 0 & 2.2 & Eubacterium \\
Unclassified & 4.4 & 16.5 & \\
Phylum Bacteroidetes & $\mathbf{5 3 . 8}$ & $\mathbf{2 9 . 7}$ & \\
Family Prevotellaceae & 29.7 & 0 & Prevotella \\
Family Bacteroidaceae & 14.3 & 11.0 & Bacteroides \\
Family Rikenellaceae & 0 & 2.2 & Alistipes \\
Unclassified & 9.9 & 16.5 & \\
Phylum Actinobacteria & $\mathbf{0}$ & $\mathbf{4 . 4}$ & Bifidobacterium, Propionibacterium \\
\hline
\end{tabular}


and VA to SA (Howard \& Henderson, 1999; Devillard et al., 2006; Kamlage et al., 1999, 2000), in a manner similar to that found in ruminal bacteria (Harfoot \& Hazlewood, 1997). The differences in metabolism between V1 and V2 tie in reasonably well with the 16S rRNA clonal analysis according to our limited understanding of intestinal biohydrogenation (Devillard et al., 2007). Pure-culture studies have shown that of the bacteria studied, Roseburia spp. and Butyrivibrio fibrisolvens metabolize LA to VA most rapidly (Devillard et al., 2007). Thus, the higher Lachnospiraceae numbers in V1 are consistent with greater biohydrogenating activity in V1. Other Firmicutes were much less active (Devillard et al., 2007), so the larger numbers of Clostridiaceae in V2 would have little impact on LA metabolism. The higher abundance of CLA isomers in V2 than V1 may reflect the higher numbers of Actinobacteria and Bacteroidetes in V1. While all Firmicutes capable of LA metabolism to CLA were found to form VA and RA as intermediates (Devillard et al., 2007), Propionibacterium and Bifidobacterium spp. (Actinobacteria) are known to produce a mixture of CLA isomers (Coakley et al., 2003; Devillard et al., 2007). Actinobacteria were not among the most numerous clones in V1, but were present in V2. Gram-negative intestinal bacteria do not metabolize LA (E. Devillard, unpublished observations), with the implication that the large difference between V1 and V2 in Bacteroidetes would have little influence on fatty acid metabolism, although it is possible that they metabolize CLA or 18:1 acids formed from LA by other species. Lactobacilli were not present in the clone libraries. Thus, although human gut-derived Lactobacillus spp. have been reported to produce CLA (Alonso et al., 2003), their low abundance and low activity suggest that their role in CLA synthesis in the mixed indigenous community is relatively minor.

The metabolic data indicate that the bacterial community in V1 contained specific bacteria capable of converting VA to SA, which were missing or inactive in V2. The bacteria capable of this step of LA metabolism are unknown. In the rumen, the only species yet isolated that forms SA as an end product of LA metabolism is C. proteoclasticum (Wallace et al., 2006). No C. proteoclasticum were present in either V1 or V2. Thus, there remains an important unknown in the microbial ecology of biohydrogenation of unsaturated fatty acids in the human colon - which species form SA? If, by analogy with the ruminal C. proteoclasticum, these bacteria carry out biohydrogenation because of an extraordinary sensitivity to growth inhibition by unsaturated fatty acids, they could prove elusive to isolate.

Such large differences in the main constituent bacteria might also have been expected to affect the main fermentation pathways in the two samples. Here, the effects were relatively minor, with the main difference apparently a lower acetate production in V1. The greater proportion of Firmicutes in V2 did not, as might have been expected based on evidence from other studies (Barcenilla et al., 2000), result in a higher proportion of butyric acid.
The measurements made in the present study were from faecal samples, from which we extrapolate to conditions prevailing in the intestine itself. The microbial community composition changes during passage of digesta through the intestine (Hayashi et al., 2005). For example, facultative anaerobes are much more abundant in caecal versus faecal samples (Marteau et al., 2001). However, we know of no study that has compared biohydrogenating activity or fatty acid-metabolizing bacteria in different sections of the gut. Furthermore, there is little indication from the study of Eckburg et al. (2005) that there are consistent changes in the Firmicutes (of which the main human biohydrogenators are members) throughout the intestine, although diversity seemed to be higher in faeces than elsewhere.

This study of faecal microbial metabolism of fatty acids from two volunteers reveals that very important differences can exist between individuals, leading to the formation of different concentrations and isomers of CLA. Such differences would be expected to have an impact upon human health, especially gut health. The systemic impact of CLA produced by the gut flora is considered to be minor, because of low absorption via the colonic epithelium (Chin et al., 1994; Kamlage et al., 1999, 2000). CLA taken up by the colonocytes may exert a local effect, however (Bassaganya-Riera et al., 2004; Miller et al., 2003). Quantities of LA passing to the intestine may be significant (Ewaschuk et al., 2006), especially in people taking dietary supplements that decrease fat absorption (Hauptman et al., 2000). A much better understanding of the microbial ecology of fatty acid metabolism will be required to use this information in a predictive manner. In particular, the bacteria responsible for SA formation must be identified. Ideally, a molecular genetic approach would offer the most promising means to search for these bacteria. However, as none of the isomerase or reductase genes has yet been identified, an approach in which the gene(s) form the target of the search is not practicable at this time.

\section{ACKNOWLEDGEMENTS}

The Rowett Research Institute receives funding from the Scottish Executive Environmental and Rural Affairs Department. D.P. was funded by the EC Framework 6 Integrated Project, 'LIPGENE'. We thank David Brown and Maureen Annand for technical help and expertise. We are grateful to Gill Campbell for the sequencing of the $16 \mathrm{~S}$ rRNA library clones. We also thank Grietje Holtrop for her help with statistical analysis.

\section{REFERENCES}

Alonso, L., Cuesta, E. P. \& Gilliland, S. E. (2003). Production of free conjugated linoleic acid by Lactobacillus acidophilus and Lactobacillus casei of human intestinal origin. J Dairy Sci 86, 1941-1946.

Barcenilla, A., Pryde, S. E., Martin, J. C., Duncan, S. H., Stewart, C. S., Henderson, C. \& Flint, H. J. (2000). Phylogenetic relationships of butyrate-producing bacteria from the human gut. Appl Environ Microbiol 66, 1654-1661. 
Bassaganya-Riera, J. \& Hontecillas, R. (2006). CLA and n-3 PUFA differentially modulate clinical activity and colonic PPAR-responsive gene expression in a pig model of experimental IBD. Clin Nutr 25, 454-465.

Bassaganya-Riera, J., Reynolds, K., Martino-Catt, S., Cui, Y., Hennighausen, L., Gonzalez, F., Rohrer, J., Benninghoff, A. U. \& Hontecillas, R. (2004). Activation of PPAR gamma and delta by conjugated linoleic acid mediates protection from experimental inflammatory bowel disease. Gastroenterology 127, 777-791.

Beppu, F., Hosokawa, M., Tanaka, L., Kohno, H., Tanaka, T. \& Miyashita, K. (2006). Potent inhibitory effect of trans-9,trans-11 isomer of conjugated linoleic acid on the growth of human colon cancer cells. J Nutr Biochem 17, 830-836.

Chin, S. F., Storkson, J. M., Liu, W., Albright, K. J. \& Pariza, M. W. (1994). Conjugated linoleic acid (9,11- and 10,12-octodecadienoic acid) is produced in conventional but not germ-free rats fed linoleic acid. J Nutr 124, 694-701.

Cho, H. J., Kim, W. K., Jung, J. I., Kim, E. J., Lim, S. S., Kwon, D. Y. \& Park, J. H. (2005). trans-10, cis-12, not cis-9,trans-11, conjugated linoleic acid decreases ErbB3 expression in HT-29 human colon cancer cells. World J Gastroenterol 11, 5142-5150.

Clement, L., Poirier, H., Niot, I., Bocher, V., Guerre-Millo, M., Krief, S., Staels, B. \& Besnard, P. (2002). Dietary trans-10,cis-12 conjugated linoleic acid induces hyperinsulinemia and fatty liver in the mouse. J Lipid Res 43, 1400-1409.

Coakley, M., Ross, R. P., Nordgren, M., Fitzgerald, G., Devery, R. \& Stanton, C. (2003). Conjugated linoleic acid biosynthesis by humanderived Bifidobacterium species. J Appl Microbiol 94, 138-145.

Cole, J. R., Chai, B., Farris, R. J., Wang, Q., Kulam, S. A., McGarrell, D. M., Garrity, G. M. \& Tiedje, J. M. (2005). The Ribosomal Database Project (RDP-II): sequences and tools for high-throughput rRNA analysis. Nucleic Acids Res 33, D294-D296.

Devillard, E., McIntosh, F. M., Newbold, C. J. \& Wallace, R. J. (2006). Rumen ciliate protozoa contain high concentrations of conjugated linoleic acids and vaccenic acid, yet do not hydrogenate linoleic acid or desaturate stearic acid. Br J Nutr 96, 697-704.

Devillard, E., McIntosh, F. M., Duncan, S. H. \& Wallace, R. J. (2007). Metabolism of linoleic acid by human gut bacteria: different routes for biosynthesis of conjugated linoleic acid. J Bacteriol 189, 25662570 .

Duncan, S. H., Louis, P. \& Flint, H. J. (2007). Cultivable bacterial diversity from the human colon. Lett Appl Microbiol 44, 343-350.

Eckburg, P. B., Bik, E. M., Bernstein, C. N., Purdom, E., Dethlefsen, L., Sargent, M., Gill, S. R., Nelson, K. E. \& Relman, D. A. (2005). Diversity of the human intestinal microbial flora. Science 308, 1635-1638.

Ewaschuk, J. B., Walker, J. W., Diaz, H. \& Madsen, K. L. (2006). Bioproduction of conjugated linoleic acid by probiotic bacteria occurs in vitro and in vivo in mice. J Nutr 136, 1483-1487.

Eyssen, H. \& Parmentier, G. (1974). Biohydrogenation of sterols and fatty acids by the intestinal microflora. Am J Clin Nutr 27, 13291340.

Fay, L. \& Richli, U. (1991). Location of double bonds in polyunsaturated fatty acids by gas chromatography-mass spectrometry after 4,4-dimethyloxazoline derivatization. J Chromatog 541, 89-98.

Flint, H. J., Duncan, S. H., Scott, K. P. \& Louis, P. (2007). Interactions and competition within the microbial community of the human colon: links between diet and health. Environ Microbiol 9, 1101-1111.

Folch, J., Lees, M. \& Soane, G. H. (1957). A simple method for the isolation and purification of total lipids from animal tissues. $J$ Biol Chem 226, 497-509.
Harfoot, C. G. \& Hazlewood, G. P. (1997). Lipid metabolism in the rumen. In The Rumen Microbial Ecosystem, pp. 348-426. Edited by P. N. Hobson \& C. S. Stewart. London: Chapman \& Hall.

Hauptman, J., Lucas, C., Boldrin, M. N., Collins, H. \& Segal, K. R. (2000). Orlistat in the long-term treatment of obesity in primary care settings. Arch Fam Med 9, 160-167.

Hayashi, H., Takahashi, R., Nishi, T., Sakamoto, M. \& Benno, Y. (2005). Molecular analysis of jejunal, ileal, caecal and recto-sigmoidal human colonic microbiota using 16S rRNA gene libraries and terminal restriction fragment length polymorphism. J Med Microbiol 54, 1093-1101.

Hontecillas, R., Wannemeulher, M. J., Zimmerman, D. R., Hutto, D. L., Wilson, J. H., Ahn, D. U. \& Bassaganya-Riera, J. (2002). Nutritional regulation of porcine bacterial-induced colitis by conjugated linoleic acid. J Nutr 132, 2019-2027.

Howard, F. A. C. \& Henderson, C. (1999). Hydrogenation of polyunsaturated fatty acids by human colonic bacteria. Lett Appl Microbiol 29, 193-196.

Kamlage, B., Hartmann, L., Gruhl, B. \& Blaut, M. (1999). Intestinal microorganisms do not supply associated gnotobiotic rats with conjugated linoleic acid. J Nutr 129, 2212-2217.

Kamlage, B., Hartmann, L., Gruhl, B. \& Blaut, M. (2000). Linoleic acid conjugation by human intestinal microorganisms is inhibited by glucose and other substrates in vitro and in gnotobiotic rats. $J$ Nutr 130, 2036-2039.

Lampen, A., Leifheit, M., Voss, J. \& Nau, H. (2005). Molecular and cellular effects of cis-9, trans-11-conjugated linoleic acid in enterocytes: effects on proliferation, differentiation, and gene expression. Biochim Biophys Acta 1735, 30-40.

Lawson, R. E., Moss, A. R. \& Givens, D. I. (2001). The role of dairy products in supplying conjugated linoleic acid to man's diet: a review. Nutr Res Rev 14, 153-172.

Lee, K. W., Lee, H. J., Cho, H. Y. \& Kim, Y. J. (2005). Role of the conjugated linoleic acid in the prevention of cancer. Crit Rev Food Sci Nutr 45, 135-144.

Marteau, P., Pochart, P., Dore, J., Bera-Maillet, C., Bernalier, A. \& Corthier, G. (2001). Comparative study of bacterial groups within the human cecal and fecal microbiota. Appl Environ Microbiol 67, 49394942.

McLeod, R. S., LeBlanc, A. M., Langille, M. A., Mitchell, P. L. \& Currie, D. L. (2004). Conjugated linoleic acids, atherosclerosis, and hepatic very-low-density lipoprotein metabolism. Am J Clin Nutr 79, 1169S$1174 \mathrm{~S}$.

Miller, A., McGrath, E., Stanton, C. \& Devery, R. (2003). Vaccenic acid (t11-18:1) is converted to c9,t11-CLA in MCF-7 and SW480 cancer cells. Lipids 38, 623-632.

O'Shea, M., Bassaganya-Riera, J. \& Mohede, I. C. (2004). Immunomodulatory properties of conjugated linoleic acid. Am J Clin Nutr 79, 1199S-1206S.

Paillard, D., McKain, N., Rincon, M. T., Shingfield, K. J., Givens, D. I. \& Wallace, R. J. (2007). Quantification of ruminal Clostridium proteoclasticum by real-time PCR using a molecular beacon approach. J Appl Microbiol 103, 1251-1261.

Richardson, A. J., Calder, G. C., Stewart, C. S. \& Smith, A. (1989). Simultaneous determination of volatile and non-volatile fermentation products of anaerobes by capillary gas chromatography. Lett Appl Microbiol 9, 5-8.

Shingfield, K. J., Ahvenjärvi, S., Toivonen, V., Ärölä, A., Nurmela, K. V. V., Huhtanen, P. \& Griinari, J. M. (2003). Effect of dietary fish oil on biohydrogenation of fatty acids and milk fatty acid content in cows. Anim Sci 77, 165-180. 
Shingfield, K. J., Reynolds, C. K., Hervás, G., Griinari, J. M., Grandison, A. S. \& Beever, D. E. (2006). Examination of the persistency of milk fatty acid composition responses to fish oil and sunflower oil in the diet of dairy cows. J Dairy Sci 89, 714-732.

Suau, A., Bonnet, R., Sutren, M., Godon, J. J., Gibson, G. R., Collins, M. D. \& Dore, J. (1999). Direct analysis of genes encoding 16S rRNA from complex communities reveals many novel molecular species within the human gut. Appl Environ Microbiol 65, 4799-4807.

Tricon, S., Burdge, G. C., Williams, C. M., Calder, P. C. \& Yaqoob, P. (2005). The effects of conjugated linoleic acid on human healthrelated outcomes. Proc Nutr Soc 64, 171-182.

Wahle, K. W., Heys, S. D. \& Rotondo, D. (2004). Conjugated linoleic acids: are they beneficial or detrimental to health? Prog Lipid Res 43, 553-587.

Wallace, R. J., Chaudhary, L. C., McKain, N., McEwan, N. R., Richardson, A. J., Vercoe, P. E., Walker, N. D. \& Paillard, D. (2006).
Clostridium proteoclasticum: a ruminal bacterium that forms stearic acid from linoleic acid. FEMS Microbiol Lett 265, 195-201.

Wang, Y. W. \& Jones, P. J. (2004). Conjugated linoleic acid and obesity control: efficacy and mechanisms. Int J Obes Relat Metab Disord 28, 941-955.

Waşowska, I., Maia, M. R. G., Niedzwiedzka, K. M., Czauderna, M., Ramalho Ribeiro, J. M. C., Devillard, E., Shingfield, K. J. \& Wallace, R. J. (2006). Influence of fish oil on ruminal biohydrogenation of C18 unsaturated fatty acids. Br J Nutr 95, 1199-1211.

Zoetendal, E. G., Akkermans, A. D. \& De Vos, W. M. (1998). Temperature gradient gel electrophoresis analysis of $16 \mathrm{~S}$ rRNA from human fecal samples reveals stable and host-specific communities of active bacteria. Appl Environ Microbiol 64, 3854-3859.

Edited by: D. M. Gordon 